core beach sand; beryllium by an electrolytic process; titanium from ilmenite and rutile; ferrochromium by means of an alumino-silico-thermal reduction method; and finally, the reduction of iron ore to produce a usable steel.

A most informative and interesting paper was given by Sir Charles Goodeve on sintering methods, which was followed by a paper on the "Efficiency of the Blast Furnace", by J. S. Vatchagandhy, S. Viswanathan and Dr. V. G. Paranjpe, of Tata Iron and Steel Co., Ltd. 'The material balance of an iron blast-furnace and an analysis of the effect of raw material changes on coke and flux requirements were discussed. The influence of chemical and thermal requirements on rate of use of coke, and the effect of high top pressure, sinter and oxygen enrichment on carbon efficiency were commented on. Comparison was made with the efficiency of the low-shaft blast furnace and direct reduction processes.

The pyro-metallurgical beneficiation of low-grade chrome ores was the subject of a paper by N. J. Wadia (Tata Iron and Steel Co., Ltd.). A method comprising the pre-treatment of high iron-content chrome ores under a reducing atmosphere at $550^{\circ} \mathrm{C}$., followed by magnetic separation, yielded a concentrate containing $37 \cdot 8-38 \cdot 9$ per cent chromium and had a $\mathrm{Cr}:$ Fe ratio of $3 \cdot 02-3 \cdot 09$.

Dr. R. Krishnaswany (Atomic Energy Establishment, Bombay) outlined a method of separating leucoxene from rutile for the manufacture of titanium. Leucoxene is an oxidation product of ilmenite and is associated with free ferric oxide; thus the magnetic properties can be improved by a reduction roast with carbon at $600 / 700^{\circ} \mathrm{C}$. and magnetic separation achieved.

The problems associated with the reduction of titania and the possibility of using vapour-phase reaction of magnesium and titanium tetrachloride were discussed in a paper by $\mathrm{Mr}$. P. P. Bhatnagar and Dr. T. Banerjee, of the National Metallurgical Laboratory, while Dr. H. N. Sinha and Prof. D. Swarup, of Banaras Hindu University, presented a paper on the "Electrolytic Production of 'Titanium".

Aluminium manufacture from bauxite by the Bayer process was covered in two papers by Dr. M. S. 'Thaker and Mr. V. V. Shah, of the Indian Aluminium Co., Ltd. Dr. E. G. Ramachandran (National Metallurgical Laboratory) presented an interesting paper on investigations carried out to determine the optimum conditions for the electrolysis of fused anhydrous aluminium chloride to yield aluminium metal and the optimum conditions for the chlorination of the ferruginous bauxite from the Salem district of Southern India. The object of the latter research was to eliminate selectively the main impurities to yield an acceptable grade of bauxite. The electrolysis experiments using pure salts and a container of nickel or graphite serving as a cathode and an anode of hard carbon or graphite, showed a current efficiency of 80 per cent and a product of 99 per cent purity. The chlorination tests on sulphided bauxite were encouraging, using a mixture of powdered bauxite and charcoal. 93 per cent iron oxide and 56 per cent titania were removed with negligible loss of alumina.

The extraction of uranium and thorium were considered by Prof. Brahm Prakash, of the Indian Institute of Science, Bangalore, in a paper entitled "Extraction of Uranium and Thorium and PyroMetallurgical Processing of Reactor Fuel and Blanket Materials".

Dr. Indra Sanghi, of the Central Electro-Chemical Research Institute, Karaikudi, on the subject of "A Method of Electrolytic Extraction of Zine from Lowgrade Ores", outlined a method suggested as a result of a study of electro-deposition of zine from alkaline zincate solutions. The practical and theoretical aspects were discussed. Tractical papers on the manufacture of zinc were presented by Mr. C. W. Thomas (Zine Corporation, Australia) and Mr. S. N. Mukherjee (Metal Corporation of India, Ltd.).

The processes employed at the Tundoo Mines of the Metal Corporation of India, Ltd., to refine silverbearing lead ores were described by J. H. Mackertoom; and lead extraction and refining in Australia were adequately dealt with by F. A. Green, of the Broken Hill Associated Smelters Pty., Ltd., Australia.

An important paper entitled "Sintering of Iron Ore Fines with Particular Reference to the Raw Materials for the Bhilai Steel Plant" was by G. P. Mathur, G. V. Subramanya and P. I. A. Narayanan. The effects of coke, moisture in the mix, basicity and raw materials proportions on the sinter time and quality have been studied in a pilot plant. Coke was shown to have a pronounced effect on sinter properties, and moisture affected permeability and sinter rate.

The symposium was very well attended by representatives from all over India and provided a vital link between the research work at the National Metallurgical Laboratory on one hand and the field workers and practical works' technicians on the other. J. L. HARRISON

\title{
OBITUARY
}

\section{Prof. Joseph W. Kennedy}

Joseph WILliam Kennedx, chairman of the Department of Chemistry at Washington University (St. Louis), died in his home at suburban Ladue in St. Louis on May 5. He was born in Nacogdoches, Texas, on May 30, 1916, the son of Joseph William and Mattie Baxter (Wade) Kennedy. He graduated from Stephen F. Austin State Teachers College in 1935 , and after receiving his master's degree from the University of Kansas in 1937 he obtained his Ph.D. in chemistry at the University of California at Berkeley in 1939. He left his position on the faculty of the University of California to lead the Chemistry and Metallurgy Division at Los Alamos during the Second World War (for which he was awarded the Medal of Merit in 1946) and has served as professor of chemistry and head of the department at Washington University since 1946.

Joseph Kennedy was considered by all of us who had the good fortune to know him well to be one of the most brilliant of scientists. He was one of the world's outstanding nuclear chemists, as well as one of the pioneers in this area of investigation. His book with G. Friedlander, "Nuclear and Radiochemistry", which is authoritative, complete and very well 
written, and certainly the outstanding text-book in the fiold, is being widely used in universities and colleges throughout the world.

$\mathrm{He}$ has a number of outstanding research accomplishments to his credit, but perhaps chief among these is his work on plutonium. He participated in the discovery of plutonium and of the isotope plutonium-239, including the demonstration of its important property of undergoing fission with slow neutrons, at the University of California during 1940 and 1941. He played a leading part in these discoveries and in the early crucial study of the chemical properties which formed the basis for the chemical extraction process used in the manufacture of plutonium during the War. In recognition of the fact that these important discoveries were made before the time of government support of research toward the goal of quantity production of plutonium, he received, two years ago, together with his coworkers, an award from the United States Government through the Atomic Energy Commission. As head of the Chemistry-Metallurgy Division at Los Alamos he had a decisive role in the important chemical and metallurgical work which was carried out in connexion with the nuclear weapon development programme.

His classic work on the chemical separation of a number of tellurium isomers was an outstanding contribution not only to the understanding of the isomers themselves but also to that of the mechanism of the chemical method of separating nuclear isomers. His more recent work has been in the general area of the application of radioactive tracers to problems in inorganic chemistry. Noteworthy here are his investigation and elucidation of a number of reaction mechanisms; he has also made important and unique contributions in the field of self-diffusion.

Joseph Kennedy had an engaging, warm personality, an alert and distinctive sense of humour which could not go unnoticed for long in any conversation, and a brilliance of intellect which was discernible almost immediately to anyone who met him. He was an excellent teacher at both the undergraduate and the graduate research-levels. $\mathrm{He}$ is survived by his wife, Adrienne, and by three children, his sons Joseph Wade and Burton Mack, and his daughter Jill.
Glenn T. Seaborg

\section{NEWS and VIEWS}

New Foreign Members of the Royal Society:

\section{Prof. H. A. Bethe}

Prof. Hans Ambrecht Bethe, who has been elected $a$ foreign member of the Royal Society, is a distinguished American theoretical physicist. Born in 1906, at Strassburg, he studied at Frankfurt and took his doctorate at Munich under Sommerfeld. He soon made notable contributions to the theory of Stark splitting in crystals, electron theory in metals, theory of energy loss of charged particles and in quantum electrodynamics. The Bethe-Heitler formula for bremsradiation, the Bethe-Peierls theory of photo-effect of the deuteron and a theory of orderdisorder phenomena in alloys date from visits of Bethe to Cambridge and Bristol between 1930 and 1935. Since 1937, Bethe has been professor of physics in Cornell University, where he has made fundamental contributions to the theory of nuclear energy production in stars, treating both the carbon cycle and deuteron fusion. He served as chief of the Theoretical Division at Los Alamos during 194346, and has played an active part as a post-war consultant to the United States Atomic Energy Commission. In 1947 Bethe successfully applied the idea of mass re-normalization in quantum electrodynamics to the explanation of the Lamb-Retherford shift of hydrogen energy-levels. Other major researches include theories of meson and nuclear scattering, meson field theory, shock waves, electromagnetic diffraction, etc. Bethe is a momber of the U.S. National Academy of Sciences and has received its Draper Medal. $\mathrm{He}$ also holds the United States Medal of Merit ; and was president of the American Physical Society in 1954. One of Bethe's major contributions to science has been the writing of superb review articles or books on the theory of metals, quantum mechanics of atomic systems, nuclear physics and field theory. These have been extremely useful to students and research workers in these fields.
Prof. A. Frey-Wyssling

Botanists the world over will applaud the inclusion by the Royal Society of London of the name of Prof. Albert Frey-Wyssling in its roll of foreign members. Frey-Wyssling has won international fame through his work on the fine structure of protoplasm and its derivatives, and his books have for many years formed a valuable addition to the literature in this field. As professor of botany in the Pflanzenphysiologisches Institut of the Eidgenössische Technische Hochschule in Zurich, he follows a line of equally distinguished predecessors, including Carl Nägeli and H. Ambronn. With the exception of two years around 1930, which he spent in Jave investigating the physiology of latex production in Hevea, Frey-Wyssling has spent his working life on submicroscopic histology. During his earlier years he was associated with Ambronn in the development of the polarizing microscope as a tool for the investigation of structure in biological material, and he played a large part in the development of polarization studies in this field. In the following years, using the polarizing microscope as an exact tool in research, he laid out for the first timo the general plan of sub. microscopic structure in many cell types. He later added the methods of $\mathrm{X}$-ray diffraction analysis and most recently of electron microscopy. He has throughout shown a remarkable ability to select the relevant pieces of evidence from a wide variety of regimes in plant science, in the formulation of structure in terms of function; and the brilliance of his extrapolation from the earlier methods to structures then invisible but since confirmed in the electron microscope has been widely recognized. A recent article by Prof. Frey.Wyssling on "Macromolecules in Cell Structure" appeared in Nature of May 11, p. 941. Much of Frey-Wyssling's work is summarized in his books, and it is a testimony to his life's work that there must be few departments of botany throughout the world in which his books are not in constant use. 